\title{
Prevalence and Antibiogram of Methicillin Resistant Staphylococcus aureus in a Tertiary Care Centre in Tumkur, India
}

\author{
Soumya Kaup $^{1}$, S. Roopashree ${ }^{1 *}$ and H.V. Balasubrahmanya ${ }^{2}$ \\ ${ }^{1}$ Department of Microbiology, Shridevi Institute of Medical Sciences and Research Hospital, \\ Sira Road, NH-04, Tumkur - 572106, India \\ ${ }^{2}$ P. C. Institute of Paramedical Sciences, Bangalore, Karnataka, India \\ *Corresponding author
}

\section{A B S T R A C T}

Methicillin Resistant Staphylococcus aureus (MRSA) has emerged as a major community acquired and nosocomial pathogen. Antibiotic armamentarium available for the treatment of MRSA infections is limited. The increasing rate of drug resistance among the isolates

\section{Keywords}

Staphylococcus aureus, MRSA, Antimicrobial resistance, Multidrug resistance.

\section{Article Info}

Accepted:

23 August 2017

Available Online:

10 September 2017 demands the judicious use of the available antibiotics. Timely collection and analysis of the antibiotic susceptibility data facilitates rational implementation of empirical therapy. The present study was conducted to evaluate the prevalence and to assess the antibiotic susceptibility patterns of the MRSA isolates from our hospital. Staphylococcus aureus isolated from all clinical samples were included in the study and subjected to antibiotic susceptibility testing. Isolates of MRSA were identified and their susceptibility pattern was analysed. Of the 240 isolates of Staphylococcus aureus obtained from various samples 109 $(45.42 \%)$ were found to be Methicillin resistant. $73.4 \%$ of the Methicillin resistant isolates were multi-drug resistant showing resistance to three or more antibiotics. The MRSA isolates showed $100 \%$ sensitivity to Vancomycin, Teicoplanin and Linezolid. In addition drugs like Amikacin, Nitrofurantoin, Netilmicin and Chloramphenicol were found to have good in-vitro activity against the isolates of MRSA. Antibiotic resistance among the MRSA isolates is increasing and treatment options available are few. Anti-MRSA drugs like Vancomycin, Teicoplanin, Linezolid, etc. should be used judiciously after appropriate antibiotic susceptibility testing. Regular monitoring of Antibiotic susceptibility pattern is essential to guide empirical therapy.

\section{Introduction}

Staphylococcus aureus is a versatile organism which on one hand is a normal human commensal and on the other is capable of causing a multitude of human infections ranging from skin afflictions to critical systemic infections. The increase in drug resistance among the isolates has contributed to its notoriety. Methicillin Resistant Staphylococcus aureus (MRSA) has emerged as a major hospital acquired and community associated public health concern due to its evolving resistance pattern. Resistance to Methicillin is mediated by SCC mec (Staphylococcal Cassette Chromosome mec) which codes for an altered Penicillin Binding Protein (PBP 2a) with decreased affinity for the $\beta$-Lactam antibiotics (Kale et al., 2016).

MRSA isolates were first reported in the year 1961, two years after Methicillin was 
introduced for the treatment of Penicillin resistant Staphylococcus aureus (Kluytmans et al., 2009; Nazari et al., 2015).The 1990's saw a paradigm shift in the epidemiology of MRSA with the emergence of community associated (CA-MRSA) isolates (Watkins et al., 2012). MRSA infections were no longer limited to the hospital milieu but also occurred in healthy individuals in the community with no predisposing factors for MRSA acquisition (Kluytmans et al., 2009). Infections caused by Methicillin resistant isolates are associated with longer hospital stays, increased costs of health care and higher mortality in invasive infections (Watkins et al., 2012).

The therapeutic armamentarium available against MRSA is limited. Periodic analysis of the susceptibility patterns of the isolates is essential to guide empirical therapy. Continued monitoring of the antibiogram of MRSA can minimize the inappropriate prescription of specific anti-MRSA drugs, when other antibiotics would be effective (Tiwari et al., 2008). Periodic evaluation of the prevalence of resistant isolates and their susceptibility patterns is essential for every hospital to guide the formulation of appropriate antibiotic policy. It is essential for the identification of the problem areas and for the institution of appropriate preventive and corrective measures. The present study was conducted to assess the prevalence and to analyse the antibiotic susceptibility patterns of isolates of MRSA from our hospital.

\section{Materials and Methods}

The study was conducted for a period of two years from January 2014 to December 2015 in the Microbiology Department of Shridevi Institute of Medical Sciences and Research Hospital, Tumkur. Staphylococcus aureus isolated from all clinical samples like pus, urine, sputum, blood and miscellaneous samples like throat swabs, vaginal swabs, body fluids from both out-patients and inpatients submitted to the Microbiology laboratory during this period were included in the study. Processing of samples and the identification of the isolates were performed by conventional methods (Collee et al., 1999).

Antimicrobial susceptibility testing was performed by Kirby-Bauer disc diffusion method and the susceptibility to antibiotics was assessed based on the Clinical Laboratory Standards Institute guidelines (CLSI, 2013).

The antibiotics tested include Penicillin-G (10units), Ampicillin $(10 \mu \mathrm{g})$, AmoxycillinClavulanic acid (20/10 $\mu \mathrm{g})$,Teicoplanin $(30 \mu \mathrm{g})$, Gentamicin $(10 \mu \mathrm{g})$, Amikacin $(30 \mu \mathrm{g})$, Netilmicin $(30 \mu \mathrm{g})$, Erythromycin $(15 \mu \mathrm{g})$, Tetracycline $(30 \mu \mathrm{g})$, Ciprofloxacin $(5 \mu \mathrm{g})$, Norfloxacin $(10 \mu \mathrm{g})$, Clindamycin $(2 \mu \mathrm{g})$,

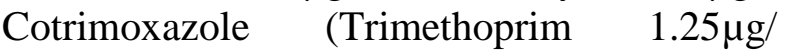
Sulfamethoxazole $23.75 \mu \mathrm{g}$ ), Choramphenicol $(30 \mu \mathrm{g})$, and Linezolid $(30 \mu \mathrm{g})$. Vancomycin MIC was assessed using E-strip. For isolates obtained from urine Nitrofurantoin $(300 \mu \mathrm{g})$ disc was added. Isolates of Staphylococcus aureus showing a zone diameter of less than $22 \mathrm{~mm}$ with Cefoxitin $(30 \mu \mathrm{g})$ disc were classified as Methicillin Resistant Staphylococcus aureus. The isolates of Methicillin Resistant Staphylococcus aureus resistant to three or more antibiotics were classified as Multi-Drug Resistant (Tiwari et al., 2008). All antibiotic discs were procured from Himedia Laboratories Pvt. Ltd. Staphylococcus aureus ATCC 25923 was used for quality control. Statistical significance was assessed by calculating $p$ value using Fisher's exact test.

\section{Results and Discussion}

A total of 240 isolates of Staphylococcus aureus were isolated from various clinical samples during the study period. Majority of 
the isolates were obtained from pus samples.109 (45.42\%) isolates were identified as Methicillin Resistant (Table 1).

Majority of the Methicillin resistant isolates were obtained in the age group of 41 to 50 years followed by 21 to 30 years (Figure 1 ).

More than $50 \%$ of the Methicillin Resistant Staphylococcus aureus (MRSA) isolates were obtained from males, though the increased isolation of MRSA isolates from males was not found to be statistically significant (Table 2).

Majority (72.48\%) of the MRSA isolates were obtained from in-patients. This finding was also not found to be statistically significant in comparison to the Methicillin sensitive isolates (Table 3).

Antimicrobial resistance patterns of the Methicillin sensitive and Methicillin resistant isolates were assessed. Methicillin resistant isolates demonstrated higher levels of resistance in comparison to the Methicillin sensitive isolates. $73.4 \%$ of the Methicillin Resistant isolates were multi-drug resistant showing resistance to three or more antibiotics.

All the isolates were sensitive to Vancomycin, Teicoplanin and Linezolid. In addition, the Methicillin resistant isolates demonstrated low level resistance to Amikacin (14.68\%),
Nitrofurantoin (16.67\%), Netilmicin (17.43\%) and Chloramphenicol (19.27\%). Ciprofloxacin and Cotrimoxazole were least effective with resistance levels of $73.39 \%$ and $69.72 \%$ respectively (Table 4 and Figure 2).

Staphylococcus aureus has continued to be an important bacterial pathogen of humans due to its ability to acquire novel strategies of drug resistance. Treatment options for drug resistant strains are limited, have more adverse effects and are more expensive (Kluytmans et al., 2009). This study was conducted to assess the prevalence of MRSA and to elaborate its antibiotic susceptibility pattern in our hospital. Majority of the isolates of $S$ aureus were obtained from pus samples. Staphylococcus aureus has been the commonest pathogen obtained from surgical site infections, purulent cellulitis and cutaneous abscesses (Tong et al., 2015).

The prevalence of the MRSA isolates in the present study was found to be $45.42 \%$ which is alarmingly high. Studies have shown that the prevalence of MRSA in different parts of India is not uniform (Tiwari et al., 2008).Variations have been seen between different regions and also between different hospitals in the same region (Joshi et al., 2013) emphasising the importance of antibiotic prescribing practices on the development of drug resistance. Table 5 lists the prevalence of MRSA in various studies across India.

Table.1 Distribution ofStaphylococcus aureus isolates from various clinical samples

\begin{tabular}{|l|c|c|c|}
\hline Sample & No. of S. aureus & No. of MRSA & \% of MRSA from each sample \\
\hline Pus & 164 & 71 & 43.29 \\
\hline Urine & 33 & 18 & 54.55 \\
\hline Sputum & 7 & 2 & 28.57 \\
\hline Blood & 24 & 13 & 54.17 \\
\hline Miscellaneous & 12 & 5 & 41.67 \\
\hline Total & $\mathbf{2 4 0}$ & $\mathbf{1 0 9}$ & $\mathbf{4 5 . 4 2}$ \\
\hline
\end{tabular}

MRSA: Methicillin Resistant Staphylococcus aureus 
Table.2 Sex distribution of the isolates

\begin{tabular}{|l|l|l|l|}
\hline & MSSA & MRSA & Total \\
\hline Male & $70(53.44 \%)$ & $60(55.05 \%)$ & $130(54.17 \%)$ \\
\hline Female & $61(46.56 \%)$ & $49(44.95 \%)$ & $110(45.83 \%)$ \\
\hline Total & 131 & 109 & 240 \\
\hline
\end{tabular}

MSSA: Methicillin Sensitive Staphylococcus aureus, MRSA: Methicillin Resistant Staphylococcus aureus; Chi square $=0.0622, \mathrm{p}$ value $=0.803087$.

Table.3 Distribution of isolates among in-patients and out-patients

\begin{tabular}{|l|l|l|l|}
\hline & MSSA & MRSA & Total \\
\hline In-patients & $85(64.89 \%)$ & $79(72.48 \%)$ & $164(68.33 \%)$ \\
\hline Out-patients & $46(35.11 \%)$ & $30(27.52 \%)$ & $76(31.67 \%)$ \\
\hline Total & 131 & 109 & 240 \\
\hline
\end{tabular}

MSSA: Methicillin Sensitive Staphylococcus aureus, MRSA: Methicillin Resistant Staphylococcus aureus; Chi square $=1.5846, \mathrm{p}$ value $=0.208102$.

Table.4 Antimicrobial Resistance Pattern of the isolates

\begin{tabular}{|c|c|c|c|c|c|}
\hline Antibiotic & $\operatorname{MSSA}(n=131)$ & $\%$ of Resistance & MRSA (n = 109) & $\%$ of Resistance & p Value \\
\hline Penicillin & 117 & 89.31 & 109 & 100 & 0.0002 \\
\hline Ampicillin & 88 & 67.18 & 109 & 100 & $<0.0001$ \\
\hline Amoxycillin-Clavulanic acid & 7 & 5.34 & 109 & 100 & $<0.0001$ \\
\hline Erythromycin & 40 & 30.53 & 74 & 67.89 & $<0.0001$ \\
\hline Clindamycin & 22 & 16.79 & 48 & 44.04 & $<0.0001$ \\
\hline Gentamicin & 8 & 6.11 & 75 & 68.81 & $<0.0001$ \\
\hline Netilmicin & 1 & 0.76 & 19 & 17.43 & $<0.0001$ \\
\hline Amikacin & 1 & 0.76 & 16 & 14.68 & $<0.0001$ \\
\hline Ciprofloxacin & 26 & 19.85 & 80 & 73.39 & $<0.0001$ \\
\hline Nitrofurantoin & $3 / 15$ & 20 & $3 / 18$ & 16.67 & 1.0000 \\
\hline Tetracycline & 12 & 9.16 & 29 & 26.61 & 0.0005 \\
\hline Chloramphenicol & 13 & 9.92 & 21 & 19.27 & 0.0426 \\
\hline Cotrimoxazole & 55 & 41.98 & 76 & 69.72 & 0.0001 \\
\hline Vancomycin & 0 & 0 & 0 & 0 & --- \\
\hline Teicoplanin & 0 & 0 & 0 & 0 & --- \\
\hline Linezolid & 0 & 0 & 0 & 0 & --- \\
\hline
\end{tabular}

Table.5 Prevalence of MRSA isolates in various parts of India from clinical samples

\begin{tabular}{|c|l|c|l|c|c|}
\hline \multicolumn{1}{|c|}{ Author } & Year & \multicolumn{1}{c|}{ Region } & No. of S. aureus & MRSA (\%) \\
\hline 1 & Vidhani et al., & 2001 & New Delhi & 188 & 51.6 \\
\hline 2 & Anupurba et al., & 2003 & Uttar Pradesh & 549 & 54.85 \\
\hline 3 & Rajaduraipandi et al., & 2006 & Tamil Nadu & 803 & 31.1 \\
\hline 4 & Pai et al., & 2010 & Karnataka & 237 & 29.1 \\
\hline 5 & Arora et al., & 2010 & Punjab & 250 & 56 \\
\hline 6 & Surpur et al., & 2013 & Karnataka & 244 & 54.91 \\
\hline 7 & Joshi et al., & 2013 & INSAR group & 26,310 & 51 \\
\hline 8 & Rupali et al., & 2014 & Maharastra & 205 & 29.7 \\
\hline 9 & Harshan et al., & 2015 & Kerala & 92 & 52.2 \\
\hline 10 & Bouchiat et al., & 2015 & Karnataka & 212 & 27.83 \\
\hline 11 & Armugam et al., & 2016 & Tamil Nadu & 1049 & 25.45 \\
\hline 12 & Bhattacharya et al., & 2016 & West Bengal & 248 & 64.9 \\
\hline 13 & Jindal et al., & 2016 & Punjab & 240 & 45.42 \\
\hline 14 & Present study & 2017 & Karnataka & & \\
\hline
\end{tabular}


Fig.1 Age-wise distribution of isolates of Staphylococcus aureus

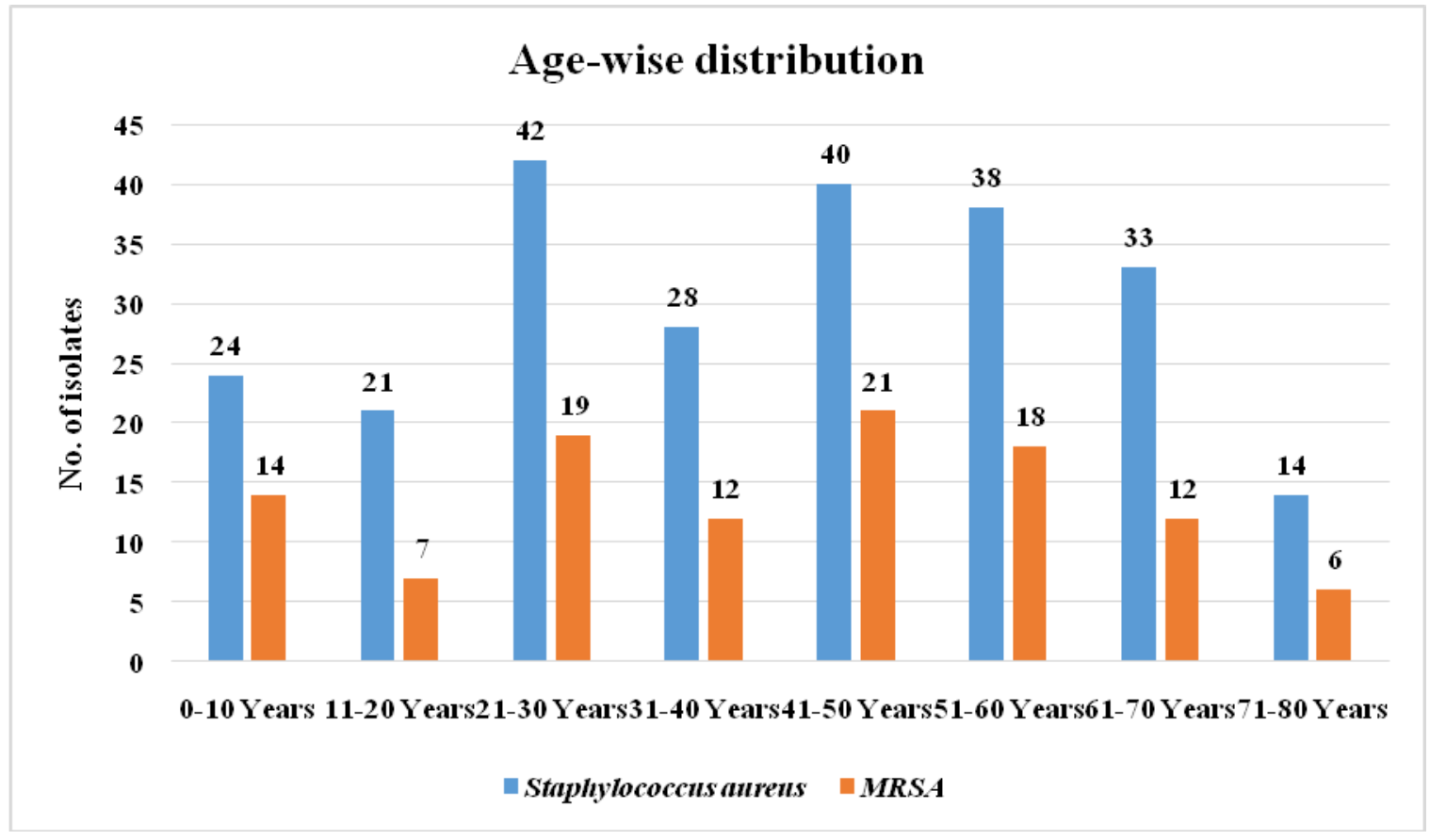

Fig.2 Antimicrobial resistance pattern of the isolates

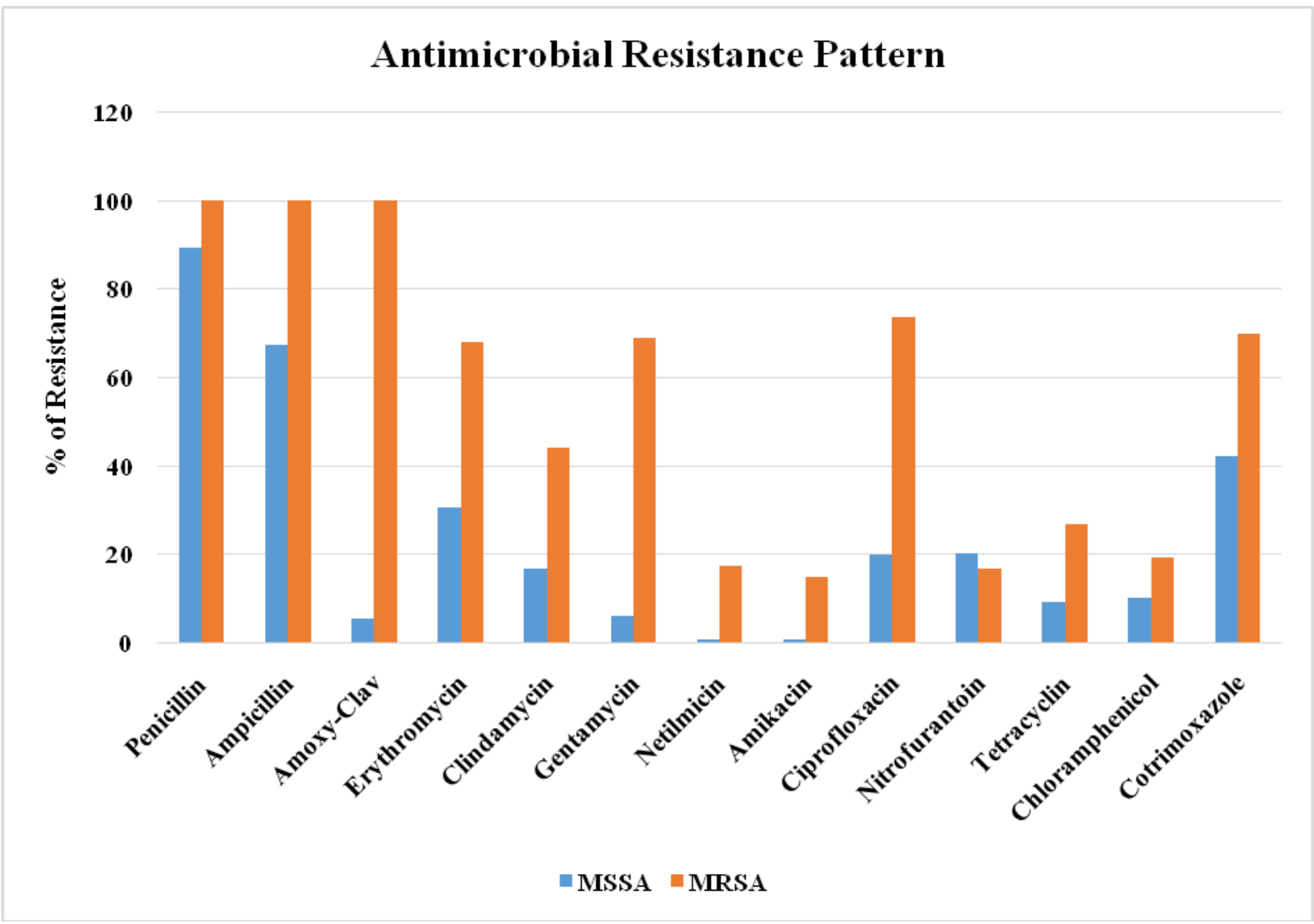


Prevalence of MRSA has been found to be high with various studies demonstrating a prevalence of more than $50 \%$ of Methicillin resistant isolates in different geographical areas.

Glycopeptides like Vancomycin are one of the main antibiotics used for the treatment of critical infections caused by MRSA (Tiwari et al., 2006). All isolates in the current study were sensitive to glycopeptides. Empirical use of these drugs without appropriate testing can lead to development of drug resistance. Vancomycin Intermediate Staphylococcus aureus (VISA) (Tong et al., 2015; Menezes et al., 2008; Bhattacharya et al., 2013) and Vancomycin Resistant Staphylococcus aureus (VRSA) (Nazari et al., 2015) have been reported from few studies in India. Development of Vancomycin resistance has further complicated the treatment of MRSA infections.

The oxazolidinone antibiotic Linezolid is another drug that has been found to be highly effective against MRSA. Global surveillance data has revealed $<1 \%$ resistance to Linezolid among $S$ aureus isolates (Gu et al., 2013). Our study did not demonstrate any Linezolid resistant isolates. Linezolid however is expensive and associated with serious adverse effects including lactic acidosis, irreversible peripheral neuropathy, anaemia, thrombocytopenia and optic neuritis when prescribed for more than 28 days. Drugs available for treatment of MRSA are limited. Antibiotics like Vancomycin and Linezolid should be used judiciously to prevent development of resistance.

Aminoglycosides like Amikacin and Netilmicin were found to be effective against MRSA, exhibiting low levels of resistance invitro. Similar results were found by other studies (Harshan et al., 2015; Arora et al., 2010).
Nitrofurantoin is an oral antibiotic used for the treatment of urinary tract infections caused by MRSA (Gould et al., 2009). Though only a few isolates from urine were studied, the isolates of MRSA showed good sensitivity to Nitrofurantoin.

Isolates of MRSA in the study have demonstrated high level of in-vitro susceptibility to Chloramphenicol. A study in Pakistan has shown good in-vitro activity of Chloramphenicol against MRSA isolates (Fayyaz et al., 2013). Antibiotics like Chloramphenicol need to be explored as alternative treatment options for MRSA infections though potential adverse effects and variable activity is a concern.

Prevalence of MRSA infections in India is demonstrating an increasing trend. Therapeutic options available against these infections are limited. Indiscriminate use of these drugs leads to development of resistance and poses further challenge for the treatment of infections caused by resistant isolates.

There is a need to review other potential antibiotics like Chloramphenicol, Netilmicin, and Amikacin as alternate treatment options for MRSA infections after appropriate susceptibility testing. Anti-MRSA drugs like Glycopeptides and Linezolid can thus be reserved for the treatment of life-threatening infections caused by MRSA.

\section{Conflict of interest}

The authors deny any conflicts of interest related to this study.

\section{Acknowledgements}

The authors acknowledge Dr. Sneha Hegadi, Assistant Professor, SIMS \& RH, Tumkur for her valuable inputs during the preparation of the manuscript. 


\section{References}

Armugam, V., Vedachalam, D., Murugesan, M., Parthasarathy, A. 2016. A study on the prevalence of Methicillin Resistant Staphylococcus aureus (MRSA) isolates from various clinical samples in a tertiary care hospital. Indian. J. Microbiol. Res. 3(1):65-68. doi:10.5958/23945478.2016.000169.

Anupurba, S., Sen, M. R., Nath, G., Sharma, B. M., Gulati, A. K., Mohapatra, T. M. 2003. Prevalence of Methicillin resistant Staphylococcus aureus in a Tertiary referral Hospital in Eastern Uttar Pradesh. Indian. J. Med. Microbiol. 21(1):49-51.

Arora, S., Devi, P., Arora, U., Devi, B. 2010. Prevalence of Methicillin-resistant Staphylococcus aurues (MRSA) in a Tertiary Care Hospital in Northern India. J. Lab. Physicians. 2(2):78-81. doi:10.4103/0974-2727.72154.

Bhattacharya, S., Pal, K., Chatterjee, M., Banerjee, M., Kundu, P. K., Niyogi, S. K. 2013. Vancomycin intermediate Staphylococcus aureus isolated from a tertiary care hospital in Kolkata. IOSR J. Dental Med. Sci. 5(2): 19-23.

Bhattacharya, S., Pal, L., Jain, S., Chatterjee, S. S., Konar, J. 2016. Surgical site infection by Methicillin-Resistant Staphylococcus aureus - on decline? J. Clin. Diagn. Res. 10(9): DC32 - DC36. doi: 10.7880/JCDR/2016/21664.8587.

Bouchiat, C., El-Zeenni, N., Chakrakodi, B., Nagaraj, S., Arakere, G., Etienne, J. 2015. Epidemiology of Staphylococcus aureus in Bangalore, India: emergence of ST217 clone and high rate of resistance to Erythromycin and Ciprofloxacin in the community. New Microbes New Infect. 14(7): 15-20.

CLSI. Performance Standards for Antimicrobial Susceptibility Testing. Twenty-Third Informational Supplement. CLSI document M100-S23. Wayne P.A.: Clinical and Laboratory Standards Institute; 2013.
Colle, J. G., Duguid J. P., Fraser, A. G., Marmion, B. P., Simons, A. Laboratory strategy in the diagnosis of infective syndromes. In: Colle, J.G., Fraser, A. G., Marmion, B. P., Simon, A, editors. Mackie \& McCartney Practical Medical Microbiology, $14^{\text {th }}$ ed. New York: Churchill Livingstone; 1999: 84-90.

Fayyaz, M., Mirza, I. A., Ahmed, Z., Abbasi, S. A., Hussain, A., Ali, S. 2013. In-vitro susceptibility of Chloramphenicol against Methicillin-Resistant Staphylococcus aureus. J. Col. Phys. Surg. Pak. 23(9): 737-640.

Gould, F. K., Brindle, R., Chadwick, P. R., Fraise, A. P., Hill, S., Nathwani, D. et al., 2009. Guidelines (2008) for the prophylaxis and treatment of Methicillinresistant Staphylococcus aureus (MRSA) infections in the United Kingdom. $J$. Antimicrob. Chemother. 63(5): 849-861. doi:10.1093/jac/dkp065

Gu, B., Kelesidis, T., Tsiodras, S., Hindler, J., Humphreis, R. M. 2013. The emerging problem of Linezolid-resistant Staphylococcus. J. Antimicrob. Chemother. 68(1): 4-11. doi:10.1093/jac/ dks354.

Harshan, K. H., Chavan, S. K. D. 2015. Prevalence and Susceptibility Pattern of Methicillin Resistant Staphylococcus aurueus (MRSA) in pus samples at a Tertiary Care Hospital in Trivandrum, India. Int. J. Curr. Microbiol. App. Sci. 4(11): 718-723.

Jindal, N., Malhotra, R., Grover, P., Singh, S., Bansal, R., Kaur, S. 2016. Methicillin Resistant Staphylococcus aureus (MRSA) in Malwa region of Punjab (Nort-West India). Indian J. Med. Res. 143(3):371372.

Joshi, S., Ray, P., Manchanda, V., Bajaj, J., Chitnis, D. S., Gautam, V, et.al. 2013. Methicillin resistant Staphylococcus aureus (MRSA) in India: Prevalence \& Susceptibility pattern. Indian Network for Surveillance of Antimicrobial Resistance (INSAR) group, India 137:363-369.

Kale, P., Dhawan, B. 2016. The changing face 
of community-acquired methicillinresistant Staphylococcus aureus. Indian. J. Med.Microbiol., 34:27585.doi:10.4103/0255-0857.188313.

Kluytmans, J., Struelens, M. 2015. Meticillin resistant Staphylococcus aureus in the hospital. BMJ, 338:b364: 53237.doi:10.1136/bmj.b364.

Menezes, G. A., Harish, B. N., Sujatha, S., Vinothini, K., Parija, S. C. 2008. Emergence of Vancomycin-Intermediate Staphylococcus species in Southern India. J. Med. Microbiol. 57:911-912.

Nazari, M.R., Sekawi, Z., Sadeghifard, N., Raftari, M., Ghafourian, S. 2015. Methicillin-resistant Staphylococcus aureus: a systematic review. Rev. Med. Microbiol. 26(1):1-7. doi:10.1097/MRM. 0000000000000023.

Pai, V., Rao, V. I., Rao, S. P. 2010. Prevalence and Antimicrobial Susceptibility Pattern of Methicillin-resistant Staphylococcus aureus (MRSA) isolates at a Tertiary Care Hospital in Mangalore, South India. J. Lab. Physicians. 2(2): 82-84. doi:10.4103/0974_2727.72155.

Rajadiraipandi, K., Mani, K. R., Paneerselvam, K., Mani, M., Bhasker, M., Manikandan, P. 2006. Prevalence and antimicrobial susceptibility pattern of Methicillin Resistant Staphylococcus aureus: A multicentre study. Indian J. Med. Microbiol. 24(1): 34-8.

Rupali, S. M., Akshay, R. K., Nitin, A. A., Sarika, P. K. 2014. Prevalence of Methicillin Resistant Staphylococcus aureus in tertiary care hospital, Central India. Int. J. Curr. Microbiol. App. Sci. 3(10)582-586.
Surpur, R. R., Patil, V. M., Rao, A., Hegadi, S., Kalpana. 2013. Prevalence of Methicillin Resistant Staphylococcus aureus and antibiotic susceptibility pattern among patients admitted at Navodaya Medical College, Hospital and Research Centre, Raichur. International Journal of Recent Trends in Science and Technology. 9(1):152-154.

Tiwari, H. K., Sapkota, D., Sen, M. R. 2008. High prevalence of multi-drug resistant MRSA in a tertiary care hospital of northern India. Infect Drug Resist. 1:5761.

Tiwari, H. K., Sen, M. R. 2006. Emergence of Vancomycin resistant Staphylococcus aureus (VRSA) from a tertiary care hospital from northern part of India.BMJ Infect. Dis. 6:156. doi:10.1186/14712334-6-156.

Tong, S. Y. C., Davis, J. S., Eichenberger, E., Holland, T. L., Fowler, V. G. Jr. 2015. Staphylococcus aureus infections: Epidemiology, Pathophysiology, Clinical Manifestations, and Management. Clin. Micobiol. Rev. 28(3):603661.doi:10.1128/CMR.00134-14.

Vidhani, S., Mehndiratta, P. L., Mathur, M. D. 2001. Study of Methicillin Resistant $S$. Aureus (MRSA) isolates from high risk patients. Indian J. Med. Microbiol. 19(2): 13-16.

Watkins, R.R., David, M. Z., Salata, R.A. 2012. Current concepts on the virulence mechanisms of methicillin-resistant Staphylococcus aureus. J. Med. Microbiol. 61:1179-93.doi:10.1099/jmm. 0.043513-0.

\section{How to cite this article:}

Soumya Kaup, S. Roopashree and Balasubrahmanya, H.V. 2017. Prevalence and Antibiogram of Methicillin Resistant Staphylococcus aureus in a Tertiary Care Centre in Tumkur, India. Int.J.Curr.Microbiol.App.Sci. 6(9): 2236-2243. doi: https://doi.org/10.20546/ijcmas.2017.609.274 